\title{
Association between Bolton discrepancy and Angle malocclusions
}

\section{Rodrigo Hermont CANÇADO Waldir GONÇALVES JÚNIOR Fabrício Pinelli VALARELLI Karina Maria Salvatore de FREITAS Janaina Aparecida Lima CRÊSPO}

Unidade de Ensino Superior Ingá, School of Dentistry, Department of Orthodontics, Maringá, PR, Brazil.

Declaration of Interests: The authors certify that they have no commercial or associative interest that represents a conflict of interest in connection with the manuscript.

Corresponding Author:

Rodrigo Hermont Cançado

E-mail: rohercan@uol.com.br

DOI: 10.1590/1807-3107BOR-2015.vol29.0116

Submitted: Jan 08, 2015

Accepted for publication: Jul 13, 2015

Last revision: Aug 27, 2015
Abstract: This study aimed to assess and compare the overall and anterior ratios of tooth size discrepancies in all Angle malocclusion groups. The following null hypothesis $\left(\mathrm{H}_{0}\right)$ was tested: no difference between tooth size discrepancies (overall and anterior) would be observed among Angle malocclusion groups. The sample comprised of 711 pre-orthodontic treatment study casts of Brazilian patients with a mean age of 17.42 years selected from private practices in Brazil. The casts were divided into 3 groups according to the type of malocclusion: Class I $(n=321)$, Class II $(n=324)$, and Class III patients $(n=66)$. The measurement of the greatest mesiodistal width of the teeth was performed using a centesimal precision digital caliper directly on the study casts, from the distal surface of the left first molar to the distal surface of the right first molar. The overall and anterior ratios between the maxillary and mandibular teeth were evaluated using Bolton's method. The following statistical tests were applied: chi-square, independent t-test, and one-way ANOVA. Results showed that all Angle malocclusions groups exhibited a ratio compatible with those recommended by Bolton. With respect to the overall and anterior ratios among the malocclusion groups, no statistically significant differences were found. The null hypothesis was accepted because the results showed no differences in the overall and anterior ratios of tooth size discrepancies among different Angle malocclusion groups.

Keywords: Odontometry; Retrospective Studies; Malocclusion.

\section{Introduction}

Several authors have expressed concerns regarding the association between the mesiodistal size of maxillary and mandibular teeth and its influence on the relationship between dental arches. ${ }^{1,2}$ Bolton $^{3,4}$ developed a method to calculate the ratio between the mesiodistal width of maxillary and mandibular teeth and stated that a correct and harmonious occlusion is possible only with adequate proportionality of tooth sizes.

Identifying the presence of tooth size discrepancies between the maxillary and mandibular arches is an important component of correct orthodontic diagnosis and treatment. The presence of such discrepancies at the beginning of the treatment influences orthodontic planning by demanding reduction (interproximal wear), increase (crowns and resins), or elimination (extractions) of dental mass prior to treatment finalization. Therefore, the orthodontist's knowledge of possible tooth size discrepancies 
plays an important role in precise planning and achieving the best possible outcome. ${ }^{5,6}$

Several studies have evaluated patients with different malocclusion groups (Class I, Class II, and Class III) that were orthodontically treated and found no statistically significant differences in the prevalence of tooth size discrepancies among the 3 groups. ${ }^{78,9}$ Basaran et al..$^{7}$ divided the casts of 300 patients into five groups based on the types of malocclusions (Class I, Class II, Class II division 1, Class II division 2, and Class III) and reported no statistically significant differences among the groups. However, other studies have observed significant differences in the presence of tooth size discrepancies among malocclusion groups. 10,11,12,13 Wedrychowska-Szulc et al. ${ }^{14}$ compared tooth size ratios in 600 study casts of patients with different malocclusion groups (Class I, Class II division 1, Class II division 2, and Class III) and found statistically significant differences in the overall ratio among all groups and in the mean ratio in the anterior region between Class I and Class III groups. Araujo and Souk $\mathrm{i}^{10}$ assessed the association between tooth size discrepancy in the anterior region and Class I, II, and III Angle malocclusions in 300 Brazilian patients. Their results showed that those with Class I and III malocclusions exhibited higher prevalence of tooth size discrepancies in the anterior region compared with those with Class II malocclusions. Moreover, the mean tooth size discrepancies in the anterior region were significantly higher in patients with Class III malocclusion than in those with Class I and Class II malocclusions.

Considering that there are very few studies that assess the association between Bolton discrepancy and Angle malocclusions, and the available literature is inconsistent. Therefore, the purpose of this study was to compare the overall and anterior Bolton ratios among different malocclusion groups using a sample from the Brazilian population.

\section{Methodology}

\section{Material}

This study was approved by the Ethics Committee of the Research of Ingá Faculty (protocol no. CAAE 0252.0.362.000-12). Prior to onset of this study, a sample size calculation was performed to determine the minimum number of individuals per group. To avoid type I error, the sample size was calculated considering $\alpha=5 \%$ (type I error), $\beta=20 \%$ (type II error), estimated variability (s) of $2.24,{ }^{14}$ and a minimum difference to be detected (d) between the groups of $1.5 \mathrm{~mm}$. The calculations yielded a sample of 62 individuals in each group (considering occasional losses), with a test power of $80 \%$. The following null hypothesis was tested: no differences in the overall and anterior ratios of tooth size discrepancies would be observed among Angle malocclusion groups.

The study sample consisted of 711 initial study casts of patients selected from the archives of private clinics in the city of Dourados, MS, Brazil. These casts were divided into three groups based on the relationship between the maxillary and mandibular first molars (Angle classification): 321 casts with Class I malocclusion and mean age of 17.93 years (SD 4.27), 324 casts with Class II malocclusion and mean age of 17.24 years (SD 4.40), and 66 casts with Class III malocclusion and mean age of 17.09 years (SD 4.65).

The following inclusion criteria were used for cast selection: presence of all completely erupted permanent teeth from the first molar of one side to the first molar of the other side; absence of previous orthodontic treatment; absence of anomalies, excessive wear, fractures, tooth caries, interproximal restorations changing the original tooth size, and any type of prosthetic rehabilitation; and absence of distortions, bubbles or fractures in the casts hampering the mesiodistal width measurements of all permanent teeth up to the first molars. The diagnosis and classification of malocclusions were based exclusively on the existing relationship between the permanent first molars and canines and was evaluated using the casts.

\section{Methods}

A digital caliper with precision of $0.01 \mathrm{~mm}$ (Stainsmaller Hardened, VTC, Ribeirão Preto, Brazil) was used to measure the mesiodistal diameters of the casts. All measurements were performed using a single, properly calibrated examiner (WGJ).

The obtained values corresponded to the greatest mesiodistal width of each tooth from the distal surface of the left first molar to the distal surface of the right first 
molar in both arches. The method proposed by Bolton ${ }^{3}$ was adopted for calculation of tooth size discrepancy. The overall ratio was calculated by dividing the sum of the mesiodistal widths of the mandibular teeth (12 teeth) by the sum of the mesiodistal widths of the maxillary teeth (12 teeth), and the anterior ratio was calculated by dividing the sum of mesiodistal widths of the mandibular anterior teeth ( 6 teeth) by the sum of mesiodistal widths of the maxillary anterior teeth (6 teeth). Considering that a clinical diagnosis of the reasons contributing to the existence of tooth size discrepancy in casts was not performed, all detected discrepancies were described as relative excess of maxillary and mandibular tooth size.

Bolton Formula

$$
\begin{aligned}
& \text { Overall Ratio }(\%)=\frac{\text { Sum of M-D diameter }(\# 36-\# 46)}{\text { Sum of M-D diameter }(\# 16-\# 26)} \times 100 \\
& \text { Anterior Ratio }(\%)=\frac{\text { Sum of M-D diameter }(\# 33-\# 43)}{\text { Sum of M-D diameter }(\# 13-\# 23)} \times 100
\end{aligned}
$$

The overall and anterior ratios of all malocclusion groups were compared with the ratios recommended by Bolton: $91.3 \pm 1.91$ and $77.2 \pm 1.65$ for overall and anterior ratio, respectively. ${ }^{4}$

\section{Statistical analysis}

One hundred pairs of casts were measured again after a 30-day interval to assess the Method Error. Dahlberg's formula was used to estimate the magnitude of random errors, and t-test was used to assess the systematic error. Descriptive statistics were used to calculate the mean age, standard deviation, and age range of the three evaluated malocclusion groups. In addition, the frequency of patients (percentage) was calculated in all malocclusion groups that showed overall and anterior discrepancies greater or smaller than 2SD associated with the ratio proposed by Bolton. ${ }^{4}$

The Kolmogorov-Smirnov test was used to evaluate data distribution, and all malocclusion groups exhibited normal distribution. Therefore, the independent t-test was used to compare the overall and anterior ratios of the malocclusion groups with the ratios recommended by Bolton.

The chi-square test was used to assess the compatibility of groups with respect to gender distribution, and the analysis of variance (one-way ANOVA) was used to compare the overall and anterior ratios among the malocclusion groups.

All statistical analysis was performed using Statistica 7.0 software for Windows (Statsoft, Tulsa, USA), with a level of significance of $p<0.05$.

\section{Results}

The magnitude of random errors ranged from 0.1712 ( $\Sigma$ of the 6 mandibular teeth) to 0.5121 ( $\Sigma$ of 12 maxillary teeth). No significant systematic error was observed during the evaluation of intra-examiner error.

The descriptive statistics of age (mean, standard deviation, and amplitude) for the three malocclusion groups are presented in Table 1.

The overall ratio of the three malocclusion groups exhibited no significant differences $(p>0.05)$ compared with the ratios recommended by Bolton. ${ }^{4}$ However, comparison of the anterior ratios of the malocclusion groups and Bolton's ratio ${ }^{4}$ showed statistically significant differences in Class I and Class II groups, whereas Class III malocclusion group exhibited similar values. These results are shown in Tables 2 and 3.

There were no significant differences observed when comparing the overall and anterior ratios among the malocclusion groups (Table 4).

Similar frequencies were observed in the groups with overall and anterior discrepancies greater or smaller than 2SD of the ratio proposed by Bolton (Tables 5 and 6).

\section{Discussion}

No statistically significant differences were found when comparing the overall ratio of each malocclusion group with Bolton's ratio, corroborating the findings of Crosby and Alexander, ${ }^{8}$ Endo et al., ${ }^{15}$ and Akyalcin et al. ${ }^{5}$

No statistically significant differences were observed in the mean overall ratio of the teeth between Class I, Class II, and Class III malocclusions groups (91.61; 91.46, and 91.22, respectively). These results corroborate the findings of Carreiro et al., ${ }^{16}$ Crosby and Alexander, ${ }^{8}$ Uysal and Sari, ${ }^{9}$ and $\mathrm{O}^{\prime}$ Mahony et al. ${ }^{17}$ However, Lavelle, Legovic et al., ${ }^{18} \mathrm{Nie}$ and Lin, ${ }^{12}$ Sperry et al., ${ }^{13}$ and Wedrychowska-Szulc et al. ${ }^{14}$ showed 
Table 1. Descriptive statistics of the initial ages of the groups evaluated.

\begin{tabular}{lcccc}
\hline Group & $\mathrm{n}$ & Mean age & SD & Range \\
\hline Class I & 321 & 17.93 & 4.27 & $10.00-37.56$ \\
Class II & 324 & 17.24 & 4.40 & $12.08-42.24$ \\
Class III & 66 & 17.09 & 4.65 & $12.16-39.80$ \\
\hline
\end{tabular}

Table 2. Comparison of the overall ratio of each group with Bolton's ratio $(91.3 \pm 1.91)$ by independent $t$ test.

\begin{tabular}{lcccccc}
\hline Group & $\mathrm{n}$ & Minimum & Maximum & Mean & SD & $\mathrm{p}$ \\
\hline Class I & 321 & 84.90 & 97.69 & 91.61 & 2.04 & 0.2941 \\
Class II & 324 & 85.46 & 99.06 & 91.46 & 2.06 & 0.5923 \\
Class III & 66 & 84.35 & 98.19 & 91.22 & 2.07 & 0.8269 \\
\hline
\end{tabular}

Table 3. Comparison of the anterior ratio of each group with Bolton's ratio $(77.2 \pm 1.65)$ by independent t-test.

\begin{tabular}{lcccccc}
\hline Group & $\mathrm{n}$ & Minimum & Maximum & Mean & SD & $\mathrm{p}$ \\
\hline Class I & 321 & 71.15 & 87.45 & 78.37 & 2.68 & $0.0019^{*}$ \\
Class II & 324 & 72.27 & 86.92 & 78.31 & 2.39 & $0.0010^{*}$ \\
Class III & 66 & 72.72 & 86.62 & 77.90 & 2.85 & 0.1101
\end{tabular}

* Statistically significant for $p<0.05$.

Table 4. Comparison of the overall and anterior ratios of tooth size discrepancies among malocclusion groups by one-way ANOVA test.

\begin{tabular}{ccccc}
\hline & $\begin{array}{c}\text { Class I } \\
n=321 \\
\text { Mean (SD) }\end{array}$ & $\begin{array}{c}\text { Class II } \\
n=324\end{array}$ & $\begin{array}{c}\text { Class III } \\
n=66\end{array}$ & \\
& Mean (SD) & Mean (SD) & \\
\hline Overall ratio & $91.61(2.04)$ & $91.46(2.06)$ & $91.22(2.07)$ & 0.3317 \\
Anterior ratio & $78.37(2.68)$ & $78.31(2.39)$ & $77.90(2.85)$ & 0.4127 \\
\hline
\end{tabular}

Table 5. Frequency of patients presenting overall Bolton discrepancy greater or smaller than 2 SD ( $<87.48$ or $>95.12)$.

\begin{tabular}{lcccc}
\hline Group & $n$ & Total (\%) & $\begin{array}{c}\text { Maxillary } \\
\text { relative excess }\end{array}$ & $\begin{array}{c}\text { Mandibular } \\
\text { relative excess }\end{array}$ \\
\hline Class I & 321 & $22(6.85 \%)$ & 9 & 13 \\
Class II & 324 & $20(6.17 \%)$ & 3 & 17 \\
Class III & 66 & $4(6.06 \%)$ & 2 & 2 \\
\hline
\end{tabular}

Table 6. Frequency of patients presenting anterior Bolton discrepancy greater or smaller than 2 SD (<73.9 or $>80.5$ ).

\begin{tabular}{lcccc}
\hline Group & $n$ & Total (\%) & $\begin{array}{c}\text { Maxillary } \\
\text { relative excess }\end{array}$ & $\begin{array}{c}\text { Mandibular } \\
\text { relative excess }\end{array}$ \\
\hline Class I & 321 & $77(23.98 \%)$ & 15 & 62 \\
Class II & 324 & $71(21.91 \%)$ & 8 & 63 \\
Class III & 66 & $16(24.24 \%)$ & 6 & 10 \\
\hline
\end{tabular}

statistically significant differences among different malocclusions groups and the overall Bolton ratio, Sperry et al..$^{13}$ and Fattahi et al. ${ }^{19}$ reported increased values of overall Bolton ratio for Class III malocclusion patients. The rationale behind these results could be the presence of significant differences among racial groups, in the dimensions and proportions of teeth. ${ }^{18}$ In most countries, including Brazil, extensive racial miscegenation hinders precise establishment of the ethnic origin of the patient. ${ }^{10,16}$

With regard to the anterior ratio, we observed statistically significant differences between Class I and Class II malocclusion groups and the Bolton's ratio. Class III malocclusion group did not show statistically significant differences compared with the averages reported by Bolton. ${ }^{3}$ These findings agree with those of Motta et al. ${ }^{20}$ who assessed 161 study casts in a Brazilian population and concluded that patients with Class III malocclusion exhibited anterior ratio averages equivalent to those reported by Bolton, ${ }^{3}$ whereas Class I and Class II exhibited anterior ratios that were different. O'Mahony et al. ${ }^{17}$ found no statistically significant differences in anterior ratio between the malocclusion groups, similar to the findings of Crosby and Alexander ${ }^{8}$ and Araujo and Souki. ${ }^{10}$

No statistically significant differences were found between the malocclusion groups when comparing the overall and anterior ratios of tooth size discrepancy. This is in agreement with the findings of Motta et al., ${ }^{20}$ Laino et al., ${ }^{21}$ Uysal and Sari, ${ }^{9}$ and Akyalcin et al. Therefore, the type of malocclusion does not influence tooth size ratio between dental arches. Lavelle ${ }^{18}$ and Sperry et al..$^{13}$ showed that patients with Class III malocclusion have a greater tendency to present tooth size discrepancy than those with Class I and Class II malocclusions. This could be explained by the type of population studied, which may influence the distribution of the tooth size ratios among the malocclusion ${ }^{10}$ groups. The results of the current study show that the type of malocclusion does not influence tooth size discrepancy between arches in the Brazilian population.

On evaluating the frequency of patients with overall Bolton discrepancy greater or smaller than 2SD $(<87.48$ or $>95.12)$, that is, the presence and location of tooth 
excesses with greater clinical significance, Class I and Class II malocclusions exhibited a predominance of relative excess in the mandibular arch (Class I had 9 patients with maxillary relative excess and 13 patients with mandibular relative excess, and Class II had 3 patients with maxillary relative excess and 17 patients with mandibular relative excess), which did not occur in Class III malocclusion (2 patients with maxillary relative excess and 2 patients with mandibular relative excess). This could be explained by the fact that Class III malocclusion shows a balance in the distribution of excess between the maxillary and mandibular arches. However Wedrychowska-Szulc et al. ${ }^{14}$ found a prevalence of relative excess in the mandibular arch in Class III malocclusion. Because Bolton's standards were obtained from patients with ideal occlusion, the fluctuation in the distribution of excess between dental arches and the malocclusion type requires the establishment of specific standards for Bolton's ratio in the different malocclusion groups. ${ }^{9,14,22}$ Carreiro et al. ${ }^{16}$ found a prevalence of relative dental excess in the mandibular arch and this corroborated with our results. The studies conducted by Bolton ${ }^{3}$ and Proffit et al. ${ }^{23}$ exhibited a low percentage of overall Bolton discrepancy higher than 2SD, probably because their samples comprised patients with ideal occlusion instead of patients requiring orthodontic treatment.

With regards to the frequency of patients with anterior Bolton discrepancy higher or smaller than 2 SD ( $<73.9$ or $>80.5)$, all the studied groups exhibited relative dental excesses, with predominance in the mandibular arch. This corroborated with several authors including Freeman et al., ${ }^{24}$ Carreiro et al.,${ }^{16}$

\section{References}

1. Lundstrm AS. Intermaxillary tooth-width ratio analysis. Eur J Orthod. 1981;3(4):285-7. doi:10.1093/ejo/3.4.285

2. Neff CW. Tailored occlusion with the anterior coefficient. Am J Orthod. 1949;35(4):309-13. doi:10.1016/0002-9416(49)90045-7

3. Bolton WA. Disharmony in tooth size and its relation to the analysis and treatment of malocclusion. Angle Orthod. 1958;28:112-30.

4. Bolton WA. The clinical application of a tooth-size analysis. Am J Orthod. 1962;48:504-29. doi:10.1016/0002-9416(62)90129-X
Crosby and Alexander. ${ }^{8}$ and Santoro et al. ${ }^{6}$ Wedrychowska-Szulc et al., ${ }^{14}$ using a sample of 600 study casts to compare the Bolton ratios in different malocclusion groups, found an anterior discrepancy higher than 2SD in $31.2 \%$ of patients when compared with Bolton's standard, and the highest values were found in Class III malocclusion. Class III malocclusion presented a higher prevalence of anterior Bolton discrepancy greater or smaller than 2 SD (24.24\%), followed by Class I (23.98\%) and Class II malocclusion groups (21.91\%). This corroborated with the studies by Nie and Lin, ${ }^{12}$ Sperry et al., ${ }^{13}$ and WedrychowskaSzulc et al., ${ }^{14}$ Based on these results, we can conclude that Class III malocclusion patients require assessment of tooth size discrepancy in the anterior region of arches to achieve correct diagnosis and obtain a static and functional occlusion meeting normal standards.

Because the number of patients with tooth size discrepancies in the anterior area exceeded that of patients with overall tooth size discrepancies, their identification and diagnosis at treatment onset is of paramount importance in all types of malocclusion, especially in patients with Class III malocclusion. Tooth size discrepancies in the anterior area may compromise treatment stability by causing crowding (post-treatment relapse) and influencing patient's overjet and overbite, thus compromising the quality of orthodontic finalization. ${ }^{8,14,17,25}$

\section{Conclusion}

No differences in the overall and anterior ratios of tooth size discrepancies were found among Angle malocclusion groups.

5. Akyalçin S, Doğan S, Dinçer B, Erdinc AM, Oncağ G. Bolton tooth size discrepancies in skeletal Class I individuals presenting with different dental angle classifications. Angle Orthod. 2006;76(4):637-43.

6. Santoro M, Ayoub ME, Pardi VA, Cangialosi TJ. Mesiodistal crown dimensions and tooth size discrepancy of the permanent dentition of Dominican Americans. Angle Orthod. 2000;70(4):303-7.

7. Basaran G, Selek M, Hamamci O, Akkus Z. Intermaxillary Bolton tooth size discrepancies among different malocclusion groups. Angle Orthod. 2006;76(1):26-30. 
8. Crosby DR, Alexander CG. The occurrence of tooth size discrepancies among different malocclusion groups. Am J Orthod Dentofacial Orthop. 1989;95(6):457-61. doi:10.1016/0889-5406(89)90408-3

9. Uysal T, Sari Z. Intermaxillary tooth size discrepancy and mesiodistal crown dimensions for a Turkish population. Am J Orthod Dentofacial Orthop. 2005;128(2):226-30. doi:10.1016/j.ajodo.2004.04.029

10. Araujo E, Souki M. Bolton anterior tooth size discrepancies among different malocclusion groups. Angle Orthod. 2003;73(3):307-13.

11. Arya BS, Savara BS, Thomas D, Clarkson Q. Relation of sex and occlusion to mesiodistal tooth size. Am J Orthod. 1974;66(5):479-86. doi:10.1016/0002-9416(74)90109-2

12. Nie $Q$, Lin J. Comparison of intermaxillary tooth size discrepancies among different malocclusion groups. Am J Orthod Dentofacial Orthop. 1999;116(5):539-44. doi:10.1016/S0889-5406(99)70186-1

13. Sperry TP, Worms FW, Isaacson RJ, Speidel TM. Tooth-size discrepancy in mandibular prognathism. Am J Orthod. 1977;72(2):183-90. doi:10.1016/0002-9416(77)90059-8

14. Wedrychowska-Szulc B, Janiszewska-Olszowska J, Stepien P. Overall and anterior Bolton ratio in Class I, II, and III orthodontic patients. Eur J Orthod. 2010;32(3):313-8. doi:10.1093/ejo/cjp114

15. Endo T, Abe R, Kuroki H, Oka K, Shimooka S. Tooth size discrepancies among different malocclusions in a Japanese orthodontic population. Angle Orthod. 2008 Nov;78(6):994-9. doi:10.2319/101007-486.1

16. Carreiro LSSPA, Raveli DB, Martins LP. [Bolton tooth size discrepancy in normal occlusion and in different types of malocclusions and its relationship to arch form and tooth positioning]. R Dental Press
Ortodon Ortop Facial. 2005;10(3):97-117. Portuguese. doi:10.1590/S1415-54192005000300011

17. O’Mahony G, Millett DT, Barry MK, McIntyre GT, Cronin MS. Tooth size discrepancies in Irish orthodontic patients among different malocclusion groups. Angle Orthod. 2011 Jan;81(1):130-3. doi:10.2319/050610-246.1

18. Lavelle CL. Maxillary and mandibular tooth size in different racial groups and in different occlusal categories. Am J Orthod. 1972;61(1):29-37. doi:10.1016/0002-9416(72)90173-X

19. Fattahi HR, Pakshir HR, Hedayati Z. Comparison of tooth size discrepancies among different malocclusion groups. Eur J Orthod. 2006;28(5):491-5. doi:10.1093/ejo/cj1012

20. Motta ATS, Rodrigues S, Quintão CCA, Capelli Jr J. Análise da discrepância de tamanho dentário em pacientes da Clínica de Ortodontia da FO/UERJ. R Dental Press Ortodon Ortop Facial. 2004;9(3):83-90. doi:10.1590/S1415-54192004000300009

21. Laino A, Quaremba G, Paduano S, Stanzione S. Prevalence of tooth-size discrepancy among different malocclusion groups. Prog Orthod. 2003;4:37-44.

22. Ta TA, Ling JY, Hagg U. Tooth-size discrepancies among different occlusion groups of southern Chinese children. Am J Orthod Dentofacial Orthop. 2001;120(5):556-8. doi:10.1067/mod.2001.118998

23. Proffit WR, Fields HW Jr, Sarver DM. Contemporary orthodontics. 4th ed. St Louis: Mosby; 2007.

24. Freeman JE, Maskeroni AJ, Lorton L. Frequency of Bolton tooth-size discrepancies among orthodontic patients. Am J Orthod Dentofacial Orthop. 1996;110(1):24-7. doi:10.1016/S0889-5406(96)70083-5

25. Johe RS, Steinhart T, Sado N, Greenberg B, JingS. Intermaxillary tooth-size discrepancies in different sexes, malocclusion groups, and ethnicities. Am J Orthod Dentofacial Orthop. 2010;138(5):599-607. doi:10.1016/j.ajodo.2008.11.031 